\title{
The effects of group composition in a strategic environment: Evidence from a field experiment ${ }^{\text {is }}$
}

\author{
John A. List ${ }^{\mathrm{a}}$, William S. Neilson ${ }^{\mathrm{b}}$, Michael K. Price ${ }^{\mathrm{c}, *, 1}$ \\ ${ }^{\text {a }}$ University of Chicago and NBER, USA \\ ${ }^{\mathrm{b}}$ University of Tennessee, USA \\ ${ }^{\mathrm{c}}$ Georgia State University and NBER, USA
}

\section{A R T I C L E I N F O}

\section{Available online 9 March 2016}

\section{Jel classification:}

$\mathrm{C} 93$

D03

Z13

\section{Keywords:}

Field experiments

Group identity

Cooperation

\begin{abstract}
A B S T R A C T
Recent theoretical and empirical studies have explored the effect of group membership and identity on individual decision-making. This line of research highlights that economic models focusing on the individual as the sole entity in the decision-making environment potentially miss critical features. This study takes this literature in a new direction by overlaying a field experiment onto a setting where groups have arisen naturally. Our experimental laboratory is large open air markets, where we are able to examine the effects of group membership on seller's collusive behavior as measured by prices and surplus allocations. This permits us to explore strategic implications of group composition. Empirical results illustrate the importance of group composition on pricing decisions, and show that deviations from Nash equilibrium are crucially related to group membership.
\end{abstract}

(c) 2016 Elsevier B.V. All rights reserved.

"The desire to earn the approval, or to avoid the contempt, of those around us is a stimulus to action which often works with some uniformity in any class of persons at a given time and place. A professional man, for instance, or an artisan will be very sensitive to the approval or disapproval of those in the same occupation, and care little for that of other people..." Alfred Marshall, Principles of Economics.

\section{Introduction}

Even though great economic philosophers have scribed of the importance of group membership and social identity on individual behavior, standard economic analysis typically eschews such forces, instead focusing on micro-level incentives when modeling individual decision-making. Recently, a research agenda within economics has begun to recognize the importance of group membership and social identity on both individual behavior and market outcomes. ${ }^{2}$ The approach in

\footnotetext{
George Akerlof, Timothy Cason, Stefano DellaVigna, Guillaume Frechette, Glenn Harrison, Liesl Koch, Botond Koszegi, George Lowenstein, Matthew Rabin, Vernon Smith, Joel Sobel, and Bart Wilson provided useful comments on earlier drafts of the study. Seminar participants at James Madison University, the University of Maryland, the University of Massachusetts, Washington State University, the Cambridge Conference on Industrial Organization, the North American meeting of the Econometric Society, the North American meeting of the Economic Science Association, and the Congress of the European Economic Association also provided useful insights. Any errors remain our own.

* Correspondence to: Department of Economics, Georgia State University, P.O. Box 3992, Atlanta, GA 30302-3992.

E-mail address: mprice25@gsu.edu (M.K. Price).

1 Tel.: +14044130080.

2 This absence of the study of groups does not extend to other disciplines, as social psychologists (e.g., Tajfel and Turner, 1979), anthropologists (e.g., Murphy, 1957), sociologists (e.g., Sumner, 1906; Coser, 1956) and political scientists (Miller et al., 1981) have explored group issues for decades.
} 
the literature revolves around exploring how group membership and group composition impact preferences, which in turn affect behavior and outcomes. An important contribution in the preference-based research is Akerlof and Kranton (2000), who add social identity as an argument in the utility function and allow disutility from deviations for societal prescriptions based on that identity.

The research program also contains a number of innovative laboratory experiments in which subjects are assigned to groups as part of the experimental protocol. In some of these experiments, such as Eckel and Grossman (2005), Charness et al. (2007), and Hargreaves Heap and Zizzo (2009), assignment of laboratory subjects to groups is random. Other experimental protocols, such as implemented by Chen and Li (2009), Klor and Shayo (2010), and Li et al. (2011) use individual characteristics as the basis for group assignment, i.e., art preference or college major. A related line of inquiry, such as Goette et al. (2006) and Leider et al. (2009), explore the impact of group identity using subjects drawn from naturally occurring groups - i.e., platoon members in the Swiss Army or students in Harvard dormitories. These studies find that regardless of how groups are formed, subjects behave more favorably to members of their own group and less favorably toward others outside of their group. Yet group salience matters - the magnitude of such effects depend crucially on the extent to which the experimental protocol triggers a group identity frame.

The literature uniformly takes a "behavioral" or preference based approach to group identity. In doing so, the literature overlooks more neoclassical features that arise as a result of group composition. This is the gap that we tend to in this study - we emphasize how group composition affects both the strategies and information available to members. Specifically, we explore how these factors impact the ability of groups to cooperate and affect prices in naturally occurring markets. In this regard, we add to a literature that has previously focused on preference-based implication of group composition.

We begin by developing a conceptual framework to compare the behavior of two distinct seller groups in a decentralized bargaining market; (i) insider only groups which contain four sellers with an ongoing relationship outside of our experimental market and (ii) mixed groups that contain three sellers in an ongoing relationship and a fourth seller who is not involved in this relationship. This distinction between groups has direct implication for the types of strategies that can be used to support and sustain anti-competitive prices.

The ongoing relationship for an insider only group introduces opportunities to sustain cooperation through threat of punishment in future interactions. Mixed groups in contrast, have an outsider who cannot be punished in subsequent interactions. In a standard, game theoretic framework, this implies that the types of cooperation that can be sustained in outsider only groups may prove infeasible for mixed groups. Yet, outsiders might make promises to cooperate to overcome the absence of later interactions. However, due to a lack of prior interaction, insiders may not be able to gauge whether outsiders are morally compelled to keep promises and thus undertake efforts to determine the outsider's compulsion to abide by agreements.

With these considerations in mind, we posit different strategies that insiders might pursue in mixed markets and describe the associated pricing dynamics. An "accommodating" strategy treats the outsider as a "competitive fringe" player and has the three insiders collude by restricting overall sales volume. A "benchmarking" strategy restricts insider volume in early periods to gauge the cooperativeness of the outsider. Pricing decisions in subsequent periods depend on what insiders learn about the outsider's "type". Finally, a "competitive" strategy foregoes any attempt at cooperation and simply follows competitive pricing.

We next present empirical evidence drawn from two distinct naturally occurring environments: open air markets and sportscard shows. ${ }^{3}$ To observe natural interactions within these markets, we examine outcomes across several multilateral, decentralized bargaining markets that include 12 buyers and 4 sellers. In each market type, we provide evidence that such markets can produce outcomes that closely approximate competitive predictions. This result is important as it shows that when such markets are allowed to function reasonably freely, there are certain predictable consequences for how they operate.

To examine the importance of group formation on the stability of cooperation, we make use of a series of exogenous variations when forming seller groups. ${ }^{4}$ When seller groups are comprised solely of local vendors they are able to sustain a stable super-competitive price. That cooperation only arises once we afford sellers the opportunity for explicit, pre-period communication is supportive of prior work highlighting that communication - not just repeated interaction - is the key drive of collusion (see, e.g., Compte, 1998; Kandori and Matsushima, 1998; Genesove and Mullin, 2001; Kuhn, 2001).

When seller groups include both local vendors and a single vendor drawn from an outside marketplace, the stability of cooperative arrangements is compromised. In such settings, prices tend toward the competitive range after a few market periods. In fact, by the final market period we fail to reject the null hypothesis of competitive pricing. By highlighting the importance of group composition on seller behavior and market prices, our results contribute to the growing body of experimental work exploring how factors such as leniency programs (Bigoni et al., 2012; Hinloopen and Soetevent, 2008;

\footnotetext{
${ }^{3}$ For an overview of the existing literature examining economic institutions and behavior in open air markets see Sherry (1990). Albert LaFarge, author of U.S. Flea Market Directory, notes that "Today's American flea market is a modern version of a phenomenon that has endured throughout history in al civilized societies - wherever there is a high concentration of people, there will be market days when they assemble for the exchange of goods and services." For a more thorough discussion on sportscard markets see List (2004).

${ }^{4}$ In this spirit, our approach shares similarity with Goette et al. (2006) who exploit random assignment to platoons during officer training in the Swiss Army as a way to exogenously vary identity within naturally-occurring groups. Yet, Goette et al. (2006) examine behavior in a very different setting prisoners' dilemma games with and without third party punishment.
} 
Apesteguia et al., 2007), demand uncertainty and/or stochastic prices (Rojas, 2012; Aoyagi and Frechette, 2008; List and Price, 2005), or market structure (Isaac and Plott, 1984; Isaac et al., 1984; Davis and Holt, 1998) impact the stability of cooperation in the marketplace.

In a deeper exploration of pricing decisions in our "outsider" markets, we observe behavior largely consistent with benchmarking. In seventy percent of all outsider sessions, insiders restrict trade in the initial period and benchmark the outsider as a type willing to cooperate in future periods. Average prices in the first period of our outsider markets are thus higher than those observed in markets comprised solely of local vendors. In subsequent market rounds, sellers in benchmarked sessions set super-competitive prices. However, benchmarking proves unstable and average prices converge towards competitive levels as cooperation unravels.

Interestingly, the observed unraveling of cooperation in benchmarked sessions is linked to perceived social connection. When sellers in a benchmarked session are of a similar race, super-competitive prices are sustained throughout all but the final trading period. In contrast, when the outside dealer is a racial minority in the marketplace, average prices in the final periods of benchmarked sessions are lower than those observed in sessions without benchmarks and fall within competitive bounds. However, when insiders fail to benchmark, prices are largely unaffected by the racial composition of the seller group.

\section{Conceptual framework}

The overarching theme of the paper is to explore how the presence of outsiders in a group changes the strategic behavior of the insiders involved in an ongoing game. Because we want to use naturally-occurring groups, a trade-off arises between using an experimental protocol that allows for the development of rigorous theoretical model on the one hand and cuing group identity on the other. Because previous studies, such as Eckel and Grossman (2005) and Charness et al. (2007), find that group salience is important we utilize an experimental game - decentralized, bilateral bargaining in the spirit of Chamberlin (1948) - that is similar to the ongoing activities of the group. Unfortunately, the underlying game is difficult to analyze using a theoretical model based on rigorous microfoundations. Instead, we develop an intuitively derived conceptual framework that captures the important elements of the underlying experimental game.

Consider a game in the spirit of the decentralized Chamberlin (1948) market with 12 buyers and 4 sellers that is repeated five times. In each round the sellers simultaneously choose quantities and these units are sold to the highest-valued buyers. To develop testable hypotheses we assume that all transactions occur at a single, market-clearing price, which turns the Chamberlin market into a four-player, asymmetric social dilemma game. The primary concern of this section is the identification of strategies the vendor group can use to support super-competitive payoffs.

We begin by delineating two categories of sellers. Insiders are sellers involved in a continuing relationship with other sellers in the group, both before and after the experiment. Outsiders, in contrast, are sellers whose only interaction with the other group members occurs during the experiment. Within this context, insiders differ from outsiders in two important ways that underlie our behavioral hypotheses. First, insiders have interacted with each other and may know things about each other before the experiment begins. In contrast, insiders cannot know anything about the outsider before the experiment begins and vice versa. Second, insiders continue to interact after the experiment ends, but by definition, such interactions cannot involve any outsiders.

Consider first a group comprised entirely of insiders. Intuitively, such a group can be viewed as one that is asked to participate in a five-period social dilemma game in between periods $t$ and $t+1$ of an infinitely-repeated background social dilemma game. In such a setting, players who were cooperating in the background game can use the supergame punishment strategies from that game to enforce cooperative behavior in the induced, foreground game. ${ }^{5}$ We refer to this as postgame punishment. Unfortunately, in our empirical application, we are only able to observe activity in the foreground game. Hence, we can neither identify postgame punishment strategies nor observe their use. Yet, we can infer the existence of postgame punishment strategies should we observe cooperation in the finitely-repeated foreground game.

The danger in relying on such an empirical strategy is that we risk introducing a theory of everything. In principal, we could state that any behavior in the foreground game arises because it was enforced by unobservable postgame punishment. We address this concern in two ways. First, we only look for predicted behavior that can be supported through the underlying uniform-pricing assumption. Second, we rule out any strategies that are coercive in that they force a group member to earn profit lower than they would in the non-cooperative stage-game equilibrium. We show that the consideration of non-coercive postgame punishment strategies provides enough bite to make meaningful predictions for the behavior.

To make this precise, consider an $n$-player game with a unique Nash equilibrium for the stage game and at most one outsider. Let $b$ denote the vector of stage-game Nash equilibrium strategies. Let $\pi(s)$ denote the vector-valued, stage-game payoff function mapping strategy combinations into payoffs for each of the $n$ players.

\footnotetext{
${ }^{5}$ The folk theorem states that cooperation in the infinitely-repeated game can occur if players' discount rates are sufficiently small. If their discount rate between periods $t$ and $t+1$ is sufficiently small to support cooperation in the ongoing game, the induced discount rate between periods in the inserted experimental game must be even lower, making cooperation in that game feasible.
} 
Table 1

Payoffs assuming uniform sales price.

\begin{tabular}{|c|c|c|c|c|}
\hline \multirow[t]{2}{*}{ Uniform price (sales) } & \multicolumn{4}{|c|}{ Profits before commission } \\
\hline & Seller 1 & Seller 2 & Seller 3 & Seller 4 \\
\hline$\$ 19(1)$ & $11, \bullet$ & 10, & $9, \cdot$ & $8, \cdot$ \\
\hline$\$ 18(2)$ & 10, & $9, \bullet$ & $8, \cdot$ & $7, \cdot$ \\
\hline$\$ 17$ (3) & $9, \bullet$ & $8, \cdot$ & $7, \cdot$ & $6, \cdot$ \\
\hline$\$ 16(4)$ & $8, \cdot$ & $7, \cdot$ & $6, \cdot$ & $5, \cdot$ \\
\hline$\$ 15(5)$ & 7,8 & 6,8 & 5,7 & 4,7 \\
\hline$\$ 14(7)$ & 6,6 & 5,6 & 4,5 & 3,5 \\
\hline$\$ 13(7)$ & 5,4 & 4,4 & 3,3 & 2,3 \\
\hline
\end{tabular}

Notes: The first payoff in each cell occurs when that seller sells one unit. The second payoff occurs when the seller sells two units when total volume exceeds 4 units.

The stage game is repeated $T$ times, and we restrict attention to supergame strategies that have a particular structure consisting of two vectors for each player, one corresponding to "cooperative" states and one corresponding to "punishment" states. For player $i$ let $c_{i}=\left(c_{i 1}, \ldots, c_{i T}\right)$ identify the stage-game strategy for each player to follow on the equilibrium path, and let $d_{i}=\left(d_{i 2}, \ldots, d_{i T}\right)$ identify the stage-game strategy for each player to follow in case of a prior defection from the equilibrium path. These punishments can only occur following defections, and so there is no need to specify a punishment for period 1 . A supergame strategy combination is a pair $(c, d)$ where $c$ is the $(n \times T)$ vector of individual cooperative strategies $c=\left(c_{1}, \ldots, c_{n}\right)$ and $d$ is the $(n \times T-1)$-vector of individual punishment strategies $d=\left(d_{1}, \ldots, d_{n}\right)$. We occasionally abuse notation by placing time subscripts rather than individual subscripts on $c$ and $d$, and these correspond the $n$-vectors of individual stage-game strategies for that period of the game. The supergame strategy for player $i$ is the contingent plan to play $c_{i 1}$ in period 1 , and in periods $t=2, \ldots, T$ play $c_{i t}$ if for each period $\tau=1, \ldots, t-1$ the observed actions were $s_{\tau}=c_{\tau}$ and play $d_{i t}$ otherwise.

Definition For an insider $i$, the strategy combination $(c, d)$ is non-coercive if for each $t=1, \ldots, T$, we have $\pi_{i}\left(c_{t}\right)+\pi_{i}\left(c_{t+1}\right)+\ldots$ $+\pi_{i}\left(c_{T}\right) \geq(T-t+1) \pi_{i}(b)$, that is, the combined payoff to player $i$ if everyone follows the cooperative strategy for the rest of the game is at least as great as if everyone switches to the stage-game Nash equilibrium strategy for the rest of the game.

Definition A non-coercive equilibrium of the supergame is a supergame strategy combination $\left(c^{*}, d^{*}\right)$ such that for each insider $i$ the cooperative strategy combination $c^{*}$ is non-coercive, and for the outsider $j$ the cooperative strategy $c_{j}^{*}$ is a best response to $\left(c^{*}, d^{*}\right)$ in every subgame.

Establishing that a strategy profile is a non-coercive equilibrium requires showing that all insiders fare at least as well in the remainder of the game as they would by repeating the stage-game Nash equilibrium, and showing that the outsider's strategy is subgame perfect given the insiders' strategies. We now characterize some non-coercive equilibria of the uniformprice Chamberlin market with and without an outsider.

Usually in finitely-repeated social dilemmas attempts at cooperation unravel because there is no incentive to cooperate in the last period. Benoit and Krishna (1985) show, however, that when the stage-game has multiple Nash equilibria, cooperative outcomes can arise in early periods but not in the last one. The idea is that players cooperate at the beginning of the game but revert to a good Nash equilibrium at the end, and punish defections from the cooperative strategy by reverting to the bad Nash equilibrium for the rest of the game. Payoff differences between the good equilibrium and the bad equilibrium provide the incentive to cooperate.

The fact that insiders participate in another game after the one we study means that the insiders can sustain cooperation in the game regardless of what the outsider does, and this gives rise to a Benoit and Krishna-like mechanism for enforcing cooperation at the beginning of the game. In the experiment the four different sellers have different induced values and therefore different payoffs. Table 1 shows the payoffs for each seller under the different pricing combinations. The rows correspond to price/volume pairs, and the first column shows the price and the sales volume consistent with that price. The next four columns show the profits to each seller. The first number in each cell corresponds to the profit from selling one unit, and the second number shows the profit from selling two when total volume is at least four. ${ }^{6}$ Nash equilibrium prices occur when volume is 7 , and there are multiple prices in this range. The worst Nash equilibrium has a price of $\$ 13$, and at that price the equilibrium has seller 1 making one transaction and the other three selling two units each. Thus, the strategy profile $b$ yields the stage-game payoff vector $(5,4,3,3)$ for the sellers $1-4$ respectively, and we call this the $\$ 13$-equilibrium.

Consider a game with three insiders and one outsider, and suppose that the insiders cooperate by selling one unit each and punish deviations by playing the \$13-equilibrium. The outsider's cooperative strategy is to sell one unit for the first $T-1$ periods and then sell 2 units in period $T$, and to punish prior defections by playing the \$13-equilibrium strategy. Absent any defections, in periods $1, \ldots, T-1$ the four sellers each sell a single unit, the market clears at a price of $\$ 16$, and the four earn ( 8 ,

\footnotetext{
${ }^{6}$ A volume of four allows every seller to sell one unit. Considerations of situations where someone sells two units but volume is less than four do not arise in the analysis that follows.

7 The vector $(a, b, c, d)$ consists of the payoffs to vendors $1,2,3$, and 4 , respectively, as each individual seller has different induced costs and therefore different profits.
} 
$7,6,5)$ each period. In period $T$ the total volume is 5 and the market-clearing price is $\$ 15$, but the payoffs depend on which seller is the outsider. The outsider's payoff is given by the second element in the $\$ 15$ row of Table 1 , while the insider's payoffs are given by the first element.

This strategy combination is non-coercive because in every period the cooperative strategy yields payoffs that are higher than the $\$ 13$-equilibrium payoffs, which can be seen by comparing the first element of the $\$ 15$ row to the $(5,4,3,3)$ payoffs from the $\$ 13$-equilibrium. It remains to establish that it is subgame perfect for the outsider, and it is sufficient to check period $T-1$. If the outsider is seller 1, then selling one unit in period $T-1$ and two units in $T$ yields 8 in each of those periods, while defecting in period $T-1$ yields a payoff of 8 in period $T-1$ but only 5 in period $T$. This is obviously lower. Looking at all four sellers, the cooperative strategy yields payoffs for the last two periods of $(8+8,7+8,6+7,5+7)$ but defecting by selling two units in period $T-1$ yields payoffs of $(8+5,8+4,7+3,7+3)$. There is no incentive for the outsider to defect in any seller role, and consequently this constitutes a non-coercive equilibrium.

There are other non-coercive equilibria as well. For insiders the above equilibrium pays $(8 T-1,7 T-1,6 T-1,5 T-1)$ where the entries correspond to the earnings from $T-1$ periods of selling a single unit at a price of $\$ 16$ and one period of selling one unit for $\$ 1$ less. The $\$ 13$-strategy yields earnings of $(5 T, 4 T, 3 T, 3 T)$. The cooperative strategy yields much higher payoffs, leaving some slack for additional non-coercive strategies that reduce insider payoffs at the beginning of the game. In particular, as long as $T \geq 3$ the strategy in which insiders sell 0 units in period 1 and one unit each remaining period is noncoercive. It generates total payoffs of $(8 T-9,7 T-8,6 T-7,5 T-6)$ compared to the $\$ 13$-equilibrium of $(5 T, 4 T, 3 T, 3 T)$. Plugging in $T=3$ yields $(15,13,11,9)$ compared to $(15,12,9,9)$ and the first vector is always at least as large as the second.

A third non-coercive equilibrium has the insiders sell one unit each period and the outsider sell two. The price stays constant at $\$ 15$ and the insiders earn $(7,6,5,4)$ each period. Finally, any of the stage-game Nash equilibria are non-coercive because they pay at least as much as the worst Nash equilibrium with price of $\$ 13$.

We hypothesize that groups will follow one of four strategies. The competitive strategy has seller 1 sell one unit each period and the others sell two each period. The accommodating strategy has the insiders sell one unit each in every period and the outsider sell two, with defections punished by playing the $\$ 13$-equilibrium strategies. In this equilibrium only insiders can defect because the outsider already sells two units every period. The benchmark 1 strategy has the insiders sell one unit each period, the outsider sell one unit for the first $T-k$ periods and sell 2 units for the remaining $k$ periods, and punishment given by the $\$ 13$-equilibrium. Finally, the benchmark 0 strategy is the same as the benchmark 1 strategy except that insiders refrain from selling in the first period.

The different strategies differ in their rationales and their predicted dynamics. The competitive equilibrium can occur whether or not there exists a postgame for insiders to punish each other for defections, but the accommodating and benchmarking equilibria require postgame punishment to make them incentive compatible. The accommodating strategy predicts a steady $\$ 15$ price, while the benchmarking strategies predict falling prices. In the benchmark 1 equilibrium prices begin at $\$ 16$ but fall to $\$ 15$ for $k \geq 1$ periods at the end, while in the benchmark 0 equilibrium prices begin at a price higher than $\$ 16$, fall to $\$ 16$, and then fall to $\$ 15$ for the last $k$ periods.

The benchmarking equilibria require further rationalization, both in terms of the naming and why the groups would play them. The difference between benchmark 1 and accommodation is that in benchmark 1 the insiders payoffs are $\$ 1$ larger at the beginning of the game than in the accommodating equilibrium. This comes directly from the price difference between the two equilibria. Benchmark 1 requires that the outsider restrict sales while accommodation does not. Insiders have no prior experience with outsiders, though, and if a mixed group reaches a verbal agreement to maintain a super-competitive price, insiders do not know how compelled the outsider will be to refrain from deviating by selling a second unit.

The benchmarking strategies are a way for insiders to determine whether the outsider will abide by such verbal agreements. If they observe the prescribed sales volume (or less) in the first round, they infer that the outsider is a cooperative type and continue to sell a single unit each in future periods. If, instead, sales volume exceeds the agreed-upon number of transactions, the outsider is assumed non-cooperative and insiders revert to competitive pricing. ${ }^{8}$

If the outsider knows his type but the insiders do not, the benchmarking strategies require that the outsider reveal information. In many setting in economics, including auction theory and principal-agent theory, inducing individuals to reveal private information entails some type of information rent. The benchmark 0 strategy has these information rents, with the outsider earning a maximum of $(11,10,9,8)$ in the different seller roles when the price is $\$ 19$ instead of $(8,7,6,5)$ when the price is $\$ 16$. One can think of the benchmark 0 strategy, then, as the benchmark 1 strategy with information rents going to the outsider.

Empirically, the existence of benchmark 1 as an equilibrium strategy in groups with non-cooperative outsiders proves critical to our understanding of observed pricing dynamics. Both the benchmark 1 strategy and symmetric collusion generate the same pattern of prices if outsiders are morally compelled to follow promises. Yet, they allow for different dynamics in the final period - particularly in groups with non-cooperative outsiders. Finding patterns of stable $\$ 16$ prices for both insider-only and mixed seller groups would lead one to hypothesize alternative explanations for insider-only group cooperation that do not rely on postgame punishment. However, finding stable $\$ 16$ prices for insider-only but not mixed groups suggests that postgame punishment is an important driver of pricing decisions.

\footnotetext{
${ }^{8}$ In many regards our benchmark strategy resembles the concept of a "bandwagon" equilibrium (Farrell and Saloner, 1985; Daughetry and Reinganum, 2011) whereby some agent types act immediately whereas others wait and only take an action if they observe a prior action by others.
} 


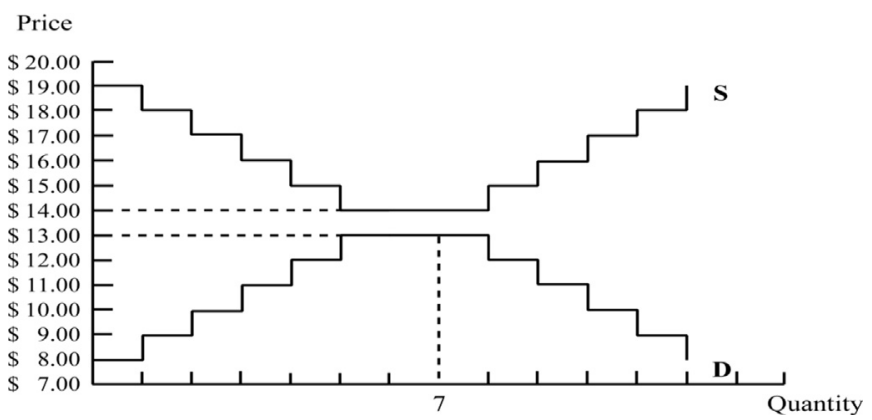

Fig. 1. Supply and Demand Structure. Note: The figure provides the induced supply and demand structure for our experimental markets. Each step on the supply (demand) function represents a unique induced marginal cost (reservation value) for a respective seller (buyer). The dashed lines provide the competitive benchmarks for this market with an equilibrium quantity of 7 units sold and an equilibrium price somewhere in the \$13-14 range.

Observing fewer than four trades in the first round followed by increased volume and falling prices, as suggested by the benchmark 0 strategy, provides evidence that insiders really do invest in learning about the outsider. Importantly, though, it means that they do not need to invest in learning about each other. Finally, finding all of these patterns supports the argument that insiders differ from outsiders in two important ways; (i) whether they continue to interact after the experiment, and (ii) whether they learn about each other from interactions prior to the experiment.

The type of benchmarking used and the success of the strategy might depend on the social distance of the insiders and outsider. Social distance could impact prior beliefs about whether the outsider is a cooperator and how much of an information rent the cooperator would require. Our sessions manipulate social distance and we can hypothesize that behavior changes when social distance does, but nothing in the theory states which direction beliefs would change as distance increases or how players should respond.

\section{Experimental design}

Subjects in our experiment are drawn from agents participants in an ongoing (background) decentralized bargaining market in the spirit of Chamberlin (1948). From this population, we randomly select 16 players to participate in our induced (foreground) market experiment - 12 from the population of buyers in the background market and 4 from the population of vendors. ${ }^{9}$ At the end of the induced (foreground) game, participants return to the ongoing (background) decentralized markets. To test the stability of cooperation, we compare pricing decisions across treatments where seller groups are comprised solely of local vendors, or insiders, and others where seller groups include both local vendors and a single vendor drawn from an outside marketplace.

In this regard, our approach shares many similarities with Leider et al. (2009) who use a field setting to explore social preferences and strategic effects in groups. However, their setting differs from ours in two important ways - the type of interaction studied and the size of the groups. First, whereas Leider et al. (2009) use variations on the dictator game to measure altruistic and efficiency-seeking motivations, we use Chamberlin markets to explore pricing decisions and the allocation of surplus. Second, the types of games examined in Leider et al. necessarily restrict groups to size two. In contrast, we use a decentralized market game that allows for larger groups comprised of four sellers.

Under our setup, each participant's experience followed four steps: (1) consideration of the invitation to participate in an experiment, (2) learning the market rules, (3) actual market participation, and (4) conclusion of the experiment and exit interview. ${ }^{10}$ In step 1, to gather the seller subject pool, a monitor randomly approached dealers before the market opened and inquired about their interest in participating in an experiment that would take about 60 min. To gather the non-dealer subject pool, the monitor randomly approached consumers entering the marketplace and inquired about their level of interest in participating in an experiment that would last $60 \mathrm{~min}$.

Once the prerequisite number of buyers (non-dealers) and sellers (dealers) agreed to participate, monitors thoroughly explained the experimental rules in step 2. The experimental instructions for the various treatments were standard and adapted from Davis and Holt $(1993,1998)$. Before proceeding, a few key aspects of the experimental design should be highlighted. First, all individuals were informed that they would receive a $\$ 10$ participation fee upon completion of the experiment. And, following Smith (1965) both buyers and sellers were provided a $\$ 0.50$ commission for each executed trade. The inclusion of a minimal commission was designed to provide incentives for trades at reservation values.

Second, buyers (non-dealers) were informed that the experiment consisted of five rounds and that they would be consumers throughout the experiment. In each round, every buyer was provided a "buyer's card" that contained a number,

\footnotetext{
${ }^{9}$ In the parlance of Harrison and List (2004) our study would thus be considered a framed field experiment.

${ }^{10}$ A portion of the experimental design discussion follows List (2004), who used bilateral trading markets to test the tenets of neoclassical theory. Additional details about the recruitment of subjects along with a copy of the experimental instructions are provided in Appendix A.
} 
Table 2

Buyer/seller reservation values (in dollars).

\begin{tabular}{|c|c|c|c|c|c|}
\hline & Round 1 & Round 2 & Round 3 & Round 4 & Round 5 \\
\hline Buyer 1 & 19 & 14 & 17 & 13 & 14 \\
\hline Buyer 2 & 18 & 9 & 10 & 17 & 11 \\
\hline Buyer 3 & 17 & 10 & 11 & 16 & 13 \\
\hline Buyer 4 & 16 & 11 & 12 & 15 & 9 \\
\hline Buyer 5 & 13 & 12 & 16 & 14 & 18 \\
\hline Buyer 6 & 14 & 13 & 14 & 19 & 15 \\
\hline Buyer 7 & 15 & 16 & 14 & 12 & 19 \\
\hline Buyer 8 & 12 & 14 & 15 & 11 & 16 \\
\hline Buyer 9 & 11 & 15 & 13 & 10 & 17 \\
\hline Buyer 10 & 10 & 17 & 18 & 9 & 14 \\
\hline Buyer 11 & 9 & 18 & 19 & 14 & 10 \\
\hline Buyer 12 & 14 & 19 & 9 & 18 & 12 \\
\hline Seller 1a & 8 & 8 & 8 & 8 & 8 \\
\hline Seller 1b & 14 & 14 & 14 & 14 & 14 \\
\hline Seller 1c & 18 & 18 & 18 & 18 & 18 \\
\hline Seller 2a & 9 & 9 & 9 & 9 & 9 \\
\hline Seller 2b & 13 & 13 & 13 & 13 & 13 \\
\hline Seller 2c & 17 & 17 & 17 & 17 & 17 \\
\hline Seller 3a & 10 & 10 & 10 & 10 & 10 \\
\hline Seller 3b & 13 & 13 & 13 & 13 & 13 \\
\hline Seller 3c & 16 & 16 & 16 & 16 & 16 \\
\hline Seller 4a & 11 & 11 & 11 & 11 & 11 \\
\hline Seller 4b & 12 & 12 & 12 & 12 & 12 \\
\hline Seller 4c & 15 & 15 & 15 & 15 & 15 \\
\hline
\end{tabular}

Table 3

Experimental design.

\begin{tabular}{|c|c|c|}
\hline & Seller composition & Experimental parameters \\
\hline $\begin{array}{l}\text { No Communication } \\
4 \text { Sessions } \\
5 \text { Rounds }\end{array}$ & All Inside Vendors & $\begin{array}{l}12 \text { Buyers - Unit Demand } \\
4 \text { Sellers - } 3 \text { Units Each } \\
\text { No Pre-Period Communication }\end{array}$ \\
\hline $\begin{array}{l}\text { Communication Insiders } \\
7 \text { Sessions } \\
5 \text { Rounds per Session }\end{array}$ & All Inside Vendors & $\begin{array}{l}12 \text { Buyers - Unit Demand } \\
4 \text { Sellers - } 3 \text { Units Each } \\
\text { Pre-Period Communication }\end{array}$ \\
\hline $\begin{array}{l}\text { Communication } \\
\text { Non-Majority Outsider } \\
10 \text { Sessions } \\
5 \text { Rounds per Session }\end{array}$ & $\begin{array}{l}\text { Three Inside Vendors matched with a Single } \\
\text { Outside Vendor }\end{array}$ & $\begin{array}{l}12 \text { Buyers - Unit Demand } \\
4 \text { Sellers - } 3 \text { Units Each } \\
\text { Pre-Period Communication } \\
\text { Outsider is Different Race than Insiders }\end{array}$ \\
\hline $\begin{array}{l}\text { Communication Majority } \\
\text { Outsider } \\
10 \text { Sessions } \\
5 \text { Rounds per Session }\end{array}$ & $\begin{array}{l}\text { Three Inside Vendors matched with a Single } \\
\text { Outside Vendor }\end{array}$ & $\begin{array}{l}12 \text { Buyers - Unit Demand } \\
4 \text { Sellers - } 3 \text { Units Each } \\
\text { Pre-Period Communication } \\
\text { Outsider is Same Race as Insiders }\end{array}$ \\
\hline
\end{tabular}

Note: Each cell represents one unique treatment in which we gathered data in different sessions. Cell entries can be read as follows. Treatment No Communication consisted of four sessions with all insider vendors and no pre-period communication amongst sellers. Each market was comprised of 12 buyers with unit demand and four sellers each of whom could supply up to three units. No subject participated in more than one session.

known only to that buyer, representing the maximum amount that he or she would be willing to pay for a single unit of the commodity. Dealers (or vendors) were informed that they would be sellers of up to three units in each market period. In each period, every vendor was provided a "seller's card" that contained numbers, known only to that seller, representing the minimum amount for which he or she would be willing to sell their respective units in the marketplace. Importantly, reservation prices were the only information provided to participants: neither buyers nor sellers were informed of the underlying support or distribution of values. Fig. 1 and Table 2 present the induced values for both buyers and sellers in our experiment, which are taken from Davis and Holt (1993). ${ }^{11}$

Third, the monitor explained how earnings (in excess of the participation fee and commissions) were determined: for sellers the difference between the actual contract price and the minimum reservation value determined producer rents. Likewise, buyers' earnings were determined by the difference between the contract price and the maximum reservation value. Several examples illustrated the irrationality associated with selling (buying) the commodity below (above) induced values.

\footnotetext{
${ }^{11}$ In Fig. 1, each step represents a distinct induced value that was given to buyers (demand curve) and sellers (supply curve).
} 
Table 4

Experimental results - summary statistics.

\begin{tabular}{|c|c|c|c|c|c|}
\hline \multirow[t]{2}{*}{ Treatment } & \multicolumn{5}{|c|}{ Market period } \\
\hline & $(1)$ & $(2)$ & $(3)$ & $(4)$ & (5) \\
\hline \multicolumn{6}{|c|}{ No Communication } \\
\hline Average price & 13.76 & 13.99 & 13.85 & 13.69 & 13.23 \\
\hline Std. deviation & $(1.6)$ & $(1.4)$ & $(0.9)$ & $(1.0)$ & $(1.2)$ \\
\hline Quantity & $(Q=6.25)$ & $(Q=7.25)$ & $(Q=7.25)$ & $(\mathrm{Q}=7.25)$ & $(Q=7.25)$ \\
\hline \multicolumn{6}{|l|}{ Profits } \\
\hline Buyers & 14.50 & 14.05 & 15.57 & 16.75 & 15.90 \\
\hline Sellers & 19.25 & 21.20 & 19.93 & 19.50 & 19.60 \\
\hline Efficiency & $91 \%$ & $95 \%$ & $96 \%$ & $98 \%$ & $96 \%$ \\
\hline \multicolumn{6}{|c|}{ Communication Insiders } \\
\hline Average price & 15.00 & 15.44 & 15.48 & 15.15 & 15.18 \\
\hline Std. deviation & $(1.7)$ & $(1.3)$ & $(1.2)$ & $(0.6)$ & $(1.3)$ \\
\hline Quantity & $(Q=3.86)$ & $(Q=3.71)$ & $(Q=4.29)$ & $(Q=4.29)$ & $(Q=5.43)$ \\
\hline \multicolumn{6}{|l|}{ Profits } \\
\hline Buyers & 7.72 & 6.93 & 6.96 & 7.66 & 8.32 \\
\hline Sellers & 17.99 & 18.64 & 20.75 & 20.06 & 25.96 \\
\hline Efficiency & $69 \%$ & $69 \%$ & $75 \%$ & $75 \%$ & $93 \%$ \\
\hline \multicolumn{6}{|c|}{ Communication Outsider Treatments Pooled } \\
\hline Average price & 16.24 & 15.56 & 15.13 & 14.41 & 13.59 \\
\hline Std. deviation & $(1.8)$ & $(1.9)$ & $(1.5)$ & $(1.3)$ & $(1.1)$ \\
\hline Quantity & $(Q=2.45)$ & $(Q=3.35)$ & $(Q=4.65)$ & $(Q=5.8)$ & $(Q=6.75)$ \\
\hline Profits & & & & & \\
\hline Buyers & 2.8 & 5.96 & 8.28 & 11 & 14.25 \\
\hline Sellers & 15.4 & 16.74 & 21.18 & 20.5 & 18.6 \\
\hline Efficiency & $49 \%$ & $61 \%$ & $79 \%$ & $85 \%$ & $89 \%$ \\
\hline \multicolumn{6}{|c|}{ Communication Majority Outsider } \\
\hline Average price & 16.60 & 15.93 & 15.46 & 14.97 & 13.98 \\
\hline Std. deviation & $(2.1)$ & $(2.2)$ & $(1.7)$ & $(1.2)$ & $(1.1)$ \\
\hline Quantity & $(Q=2.3)$ & $(Q=2.8)$ & $(Q=4.1)$ & $(Q=5.5)$ & $(Q=6.5)$ \\
\hline \multicolumn{6}{|l|}{ Profits } \\
\hline Buyers & 2.15 & 4.6 & 7.2 & 8.85 & 13.00 \\
\hline Sellers & 14.95 & 15.4 & 20.0 & 22.75 & 21.00 \\
\hline Efficiency & $46 \%$ & $54 \%$ & $74 \%$ & $85 \%$ & $92 \%$ \\
\hline \multicolumn{6}{|c|}{ Communication Non-Majority Outsider } \\
\hline Average price & 15.90 & 15.30 & 14.88 & 13.89 & 13.23 \\
\hline Std. deviation & $(1.4)$ & $(1.5)$ & $(1.4)$ & $(1.2)$ & $(1.0)$ \\
\hline Quantity & $(Q=2.6)$ & $(Q=3.9)$ & $(Q=5.2)$ & $(Q=6.1)$ & $(Q=7.0)$ \\
\hline \multicolumn{6}{|l|}{ Profits } \\
\hline Buyers & 3.45 & 7.32 & 9.35 & 13.15 & 15.50 \\
\hline Sellers & 15.85 & 18.08 & 22.35 & 18.25 & 16.20 \\
\hline Efficiency & $52 \%$ & $69 \%$ & $86 \%$ & $85 \%$ & $86 \%$ \\
\hline
\end{tabular}

Note: Figures in the table represent averages across all experimental markets within a treatment. Summary statistics are provided for period price, standard deviation of period price, quantity traded in period, and total buyer and seller profits in each period. Period 1 of the No Communication sessions had an average trading price of $\$ 13.76$ with a standard deviation of $\$ 1.60$. On average 6.25 cards were purchased, and total buyer (seller) profit was $\$ 14.50$ (\$19.25) for the period. Overall market efficiency was $91 \%$.

Fourth, the homogenous commodities used in the flea market (sportscard) experiments were compact disks that had been broken into two pieces (1992 Topps Cal Ripken baseball cards). Thus, the assignment given to sellers was clear, and an everyday occurrence: sell the compact disc (Ripken card) for as much as possible. Likewise, the task confronting buyers was also clear: enter the marketplace and purchase one compact disc (Ripken card) for as little as possible. The experimental commodities and participating dealers were clearly marked to ensure that buyers had no trouble finding the commodity of interest. Finally, buyers and sellers engaged in two five-minute practice periods to gain experience with the market.

In step 3, subjects participated in the market. Each market session consisted of 5 market periods that lasted 10 min each. After each 10-min period, a monitor privately gathered with buyers and gave them a new buyer's card while a different monitor privately gave sellers a new seller's card. During the experiment, buyers mill around the marketplace and approach dealers who are situated at clearly marked tables throughout the floor of the sportscard show (flea market) to bilaterally negotiate the purchase of the Ripken card (compact disc).

It should be noted that throughout the competitive market sessions, careful attention was given to prohibit discussion amongst sellers (buyers). In the collusive treatments, explicit seller communication was permitted. We followed Davis and Holt (1998) in our information allowance - i.e., subjects were not allowed to discuss non-public information, post-session sided payments, or threats of a physical nature. Step 4 completed the experiment - subjects completed a survey and were paid their earnings in private. 


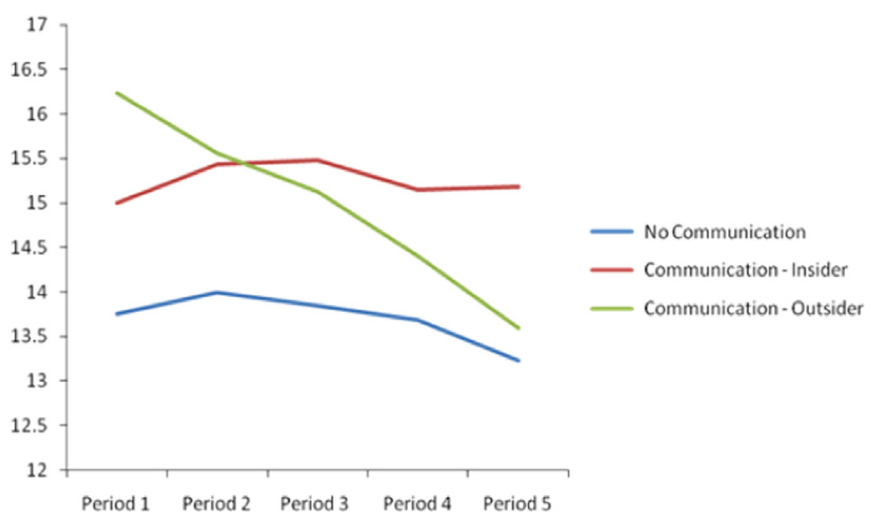

Fig. 2. Average transaction prices - pooled outsider treatments.

This procedure was followed in each of our experimental treatments. Table 3 summarizes the experimental design. Table 3 can be read as follows: row 1 contains treatment No Communication which included four sessions of twelve buyers with unit demand and four local (or inside) vendors who can each supply up to three units of the commodity. In this treatment, we prohibited pre-period communication amongst sellers. Treatment Communication Insiders is identical to treatment No Communication except that we allow explicit pre-period communication amongst sellers. In both of these treatments, "inside" vendors for sessions run at the flea market were black females who had purchased a table at the flea market and were engaged in the sale of DVD/CDs. For sessions run in the sportscard market, "inside" vendors were Caucasian males that reside in the East Coast (Southeastern) market where the experiments were conducted.

Treatment Communication Majority Outsider allows pre-period communication amongst a seller group comprised of three DVD/CD vendors from the flea market and one black female vendor who is also at the flea market, but who is engaged in selling produce (i.e., watermelon, cantaloupe, etc.). Treatment Communication Non-Majority Outsider is identical to this treatment except the "outside" vendor is a white female who is selling produce. Since a majority of vendors in our flea markets are black, the "outsider" in Treatment Communication Majority Outsider (Treatment Communication Non-Majority Outsider) represents a racial majority (minority) in the marketplace. Importantly subjects are provided no information regarding the formation of seller groups in the various treatments nor are they provided information regarding the identity of the "outside" dealer.

We employed a similar experimental design for the "outsider" treatments in the sportscard market. Yet, in this case rather than group sellers across different product lines, we formed the groups using all sportscard dealers but varied the composition by exploring behavior across two markets: a Southeast market and an East Coast market. In these cases, we include three white male local dealers and one non-local dealer in the seller group. In treatments carried out in the Southeast market the locals where drawn from the Southeast market and the non-local from the East Coast market and vice versa.

Before proceeding, it is important to note that the "outside" vendor in all sporstcard treatments was recruited from actual market participants. Hence, the "outsider" in the Southeast market was a sportscard dealer from an East Coast city that had purchased a table and traveled to the Southeast market to sell his merchandise at the regional collectables show where we ran the experiments. As the majority agent in the sportscard market is a Caucasian male, the "outside" vendor in Treatment Communication Majority (Non-Majority) Outsider was a Caucasian (black) male.

In summary, in each treatment the monitor gives each buyer (seller) a reservation price for one (three) units of a commodity (either a broken compact disc or Cal Ripken baseball card) and allows agents to engage in bilateral haggling and bargaining until they enact a contract(s) or the trading period terminates. After each contract is completed, (i) a monitor posts the exchange price on a public board, and (ii) monitors inform all buyers and sellers of the exchange price in case they are removed from the public board. In total, the experiment includes data from 31 unique experimental sessions (155 market periods). Since each buyer and seller competed in only a single treatment determined randomly, our experiment included 496 subjects: 372 consumers and 124 dealers.

\section{Experimental results}

We begin by summarizing results suggesting that the Chamberlin (1948) institution produces outcomes that closely approximate competitive predictions, and that explicit seller communication influences market outcomes when all sellers are drawn from a group of local (inside) vendors. ${ }^{12}$ Consider Table 4 , which summarizes data from our experimental treatments. Entries in Table 4 are at the period level and include average price and its standard deviation, quantity traded,

\footnotetext{
12 Throughout the empirical analysis we pool data from sessions run in the flea market with those run in the sportscard market as the qualitative nature of differences in behavior across treatments are similar across these marketplaces. Disaggregated results that examine behavior in each market separately are available from the authors upon request.
} 
Table 5

Estimated transaction prices - pooled outsider markets.

\begin{tabular}{|c|c|c|c|c|}
\hline & Model A & Model B & Predicted Price Period 1 & Predicted Price Period 5 \\
\hline \multirow{2}{*}{$\begin{array}{l}\text { Model Constant - Avg Price in Period } 1 \text { of Baseline } \\
\text { Treatment }\end{array}$} & $13.76^{* * *}$ & $13.65^{* * * *}$ & $\$ 13.76$ & $\$ 13.23$ \\
\hline & $(0.31)$ & $(0.31)$ & [13.15-14.37] & [12.83-13.63] \\
\hline \multirow[t]{2}{*}{ Indicator for Communication Insider Treatment } & $1.24^{* * *}$ & $1.48^{* * *}$ & $\$ 15.00$ & $\$ 15.18$ \\
\hline & $(0.48)$ & $(0.41)$ & {$[14.27-15.72]$} & [14.69-15.67] \\
\hline \multirow[t]{2}{*}{ Indicator for an Outsider Treatment } & $2.50 * *$ & $2.73^{* * \cdots}$ & $\$ 16.26$ & $\$ 13.59$ \\
\hline & $(0.44)$ & $(0.36)$ & [15.64-16.89] & {$[13.38-13.80]$} \\
\hline \multirow[t]{2}{*}{ Indicator for Period 2 in the Baseline Treatment } & 0.23 & 0.23 & & \\
\hline & $(0.45)$ & $(0.31)$ & & \\
\hline \multirow[t]{2}{*}{ Indicator for Period 3 in the Baseline Treatment } & 0.09 & 0.19 & & \\
\hline & $(0.29)$ & $(0.31)$ & & \\
\hline \multirow[t]{2}{*}{ Indicator for Period 4 in the Baseline Treatment } & -0.07 & -0.02 & & \\
\hline & $(0.38)$ & $(0.31)$ & & \\
\hline \multirow[t]{2}{*}{ Indicator for Period 5 in the Baseline Treatment } & $-0.53 *$ & -0.45 & & \\
\hline & $(0.31)$ & $(0.31)$ & & \\
\hline \multirow[t]{2}{*}{ Indicator for Period 2 in the Insider Treatment } & 0.21 & 0.15 & & \\
\hline & $(0.57)$ & $(0.44)$ & & \\
\hline \multirow[t]{2}{*}{ Indicator for Period 3 in the Insider Treatment } & 0.39 & 0.27 & & \\
\hline & $(0.48)$ & $(0.44)$ & & \\
\hline \multirow[t]{2}{*}{ Indicator for Period 4 in the Insider Treatment } & 0.22 & 0.24 & & \\
\hline & $(0.54)$ & $(0.43)$ & & \\
\hline \multirow[t]{2}{*}{ Indicator for Period 5 in the Insider Treatment } & 0.71 & 0.51 & & \\
\hline & $(0.50)$ & $(0.42)$ & & \\
\hline \multirow[t]{2}{*}{ Indicator for Period 2 in the Outsider Treatments } & $-0.93^{*}$ & $-0.93^{* * *}$ & & \\
\hline & $(0.56)$ & $(0.38)$ & & \\
\hline \multirow[t]{2}{*}{ Indicator for Period 3 in the Outsider Treatments } & $-1.22^{* * *}$ & $-1.27^{* * *}$ & & \\
\hline & $(0.45)$ & $(0.37)$ & & \\
\hline \multirow[t]{2}{*}{ Indicator for Period 4 in the Outsider Treatments } & $-1.79^{* *}$ & $-1.88^{* * *}$ & & \\
\hline & $(0.50)$ & $(0.37)$ & & \\
\hline \multirow[t]{2}{*}{ Indicator for Period 5 in the Outsider Treatments } & $-2.14 * *$ & $-2.29^{* * *}$ & & \\
\hline & $(0.45)$ & $(0.36)$ & & \\
\hline \multirow[t]{2}{*}{ Control for Unobserved Heterogeneity } & Clustered Standard & Random & & \\
\hline & Errors & Effects & & \\
\hline \# of Observations & 752 & 752 & & \\
\hline
\end{tabular}

* Denotes statistical significance at the $p<0.10$ level.

** Denotes statistical significance at the $p<0.05$ level.

total buyer and seller per period profits, and a measure of overall market efficiency (total rents captured divided by total available rents). Cell entries for Table 4 can be read as follows: in period 1 of our No Communication sessions, we observed an average trade volume of 6.25 units and an associated average trading price of $\$ 13.76$. Total buyer and seller profits were $\$ 14.50$ ( $\$ 19.25$ ) respectively and traders captured approximately $91 \%$ of the available surplus.

As noted in the upper panel of Table 4, Chamberlin markets yield outcomes that are compatible with competitive predictions when communication amongst sellers is prohibited: average prices are within the competitive range (\$13-14) in all periods and average quantity levels are within a single unit of the competitive benchmark ( 7 units traded). Efficiency rates are quite high ranging from approximately $91 \%$ in period 1 to nearly $98 \%$ in period 4 . This result, which is consonant with previous findings in the literature that use different institutions, sample pools, and markets (see, e.g., Hong and Plott, 1982, Joyce (1983), Grether and Plott (1984), List, (2004), List and Price, 2005), serves as a useful benchmark for examining the effect of group formation on market outcomes and the stability of explicit seller conspiracies.

\subsection{Group formation and the stability of cooperation}

We next examine the effect of allowing explicit pre-period communication amongst sellers on observed market outcomes. To this aim, consider the second panel of Table 4 which provides mean performance measures for treatment Communication Insider where seller groups are comprised solely of local vendors - i.e., insiders engaged in an ongoing relationship. As noted in Table 4, average prices for these sessions lie substantially above competitive benchmarks and are within 6.25\% (\$1.00) of the joint profit-maximizing level of $p=\$ 16.00$ in all periods. ${ }^{13}$ On average, quantities exchanged are

\footnotetext{
${ }^{13}$ Using average prices at the period level as the unit of observation, we are able to reject the null hypothesis of equal prices in treatments No Communication and Communication at the $p<0.01$ level using both a non-parametric Mann Whitney test and parametric $t$-test for differences in means. It should be noted, however, that both tests rely upon an assumption that price realizations are independent within any given period of a session. Given that this assumption is not likely met in practice, we supplement the analysis below with evidence from a series of linear regressions that explicitly control for such dependencies.
} 
at least one and a half units below those associated with competitive outcomes and in all periods efficiency levels are significantly lower than those realized in our baseline markets.

To examine the stability of cooperation in this treatment, consider differences in average trading prices across the initial and final market periods. Using a matched pairs $t$-test, we are unable to reject the null of no difference in average prices across the first and last trading period: the approximate $\$ 0.28$ difference in average prices (\$15.52 versus $\$ 15.24)$ across these rounds is not statistically significant at any meaningful level. Perusal of these data suggests a first result:

Result 1. When all sellers are drawn from a group of local (inside) vendors, anti-competitive pricing (cooperation) is sustained throughout all market periods.

Fig. 2 plots average prices by period for both our baseline No Communication treatment and treatment Communication Insiders and highlights data patterns consistent with Result 1. As illustrated in the figure, average trading prices in the latter treatment are significantly higher than those observed in our baseline markets and are remarkably stable across periods there is no discernable difference in average prices across the initial and final market periods.

Statistical support for Result 1 can be obtained by estimating an equation of individual transaction prices. To gain insights into factors that influence observed transaction prices, we estimate conditional transaction prices as:

$$
P_{i j}=\beta^{\prime} X_{i j}+e_{i j}
$$

where $P_{i j}$ is the transaction price for the $j$ th unit sold by seller $i$; $X_{i j}$ includes the treatment effect dichotomous variables (where treatment no communication is the baseline) and the interaction of the treatment effect dichotomous variables with period effects. We control for potential heterogeneity that would be left uncontrolled in a standard cross-sectional model by clustering standard errors around unique seller identification numbers or including seller specific random effects.

Empirical estimates for our model are presented in the first two columns of Table 5. The rightmost two columns of the table provide the predicted trading price and associated 95\% confidence interval across treatments for the initial and final trading periods, respectively. Columns 1 and 2 of Table 5 provide insights consistent with the price realizations in Result 1: average transaction prices in the Communication Insider treatment are higher than those observed in our baseline No Communication treatment and there is no discernable difference in average prices across the initial and final trading period. For example, average prices in the initial trading period in the Communication Insider treatment are approximately $\$ 1.24$ higher ( $\$ 15.00$ versus $\$ 13.76$ ) than those observed in our baseline treatment - a difference that is significant at the $p<0.05$ level. Importantly, this difference is sustained throughout the experiment: the predicted price in the final trading period is approximately $\$ 1.95$ greater (\$15.18 versus $\$ 13.23$ ) in our Communication Insider treatment. Moreover, we are unable to reject the null of price stability for our "insider" treatment. The approximate $\$ 0.18$ difference in average prices across the initial and final periods of this treatment is not significant at any meaningful level.

Importantly, these data are supportive of the work suggesting that communication - not just repeated interaction - is the key driver of collusion (see, e.g., Compte, 1998; Kandori and Matsushima, 1998; Genesove and Mullin, 2001; Kuhn, 2001). In our setting, sellers in the baseline should be able to tacitly collude; but, they are unable to do so and only sustain anticompetitive prices when we allow explicit communication. This result suggests that communication and repeated interaction serve as important complements to anti-competitive pricing. ${ }^{14}$

\subsection{Pricing decisions in markets with an "outside" seller}

The middle panel of Table 4 provides mean performance measures at the period level pooled across our two "outsider" treatments - Communication Majority and Non-Majority Outsider. In the initial trading period, average prices in our pooled "outsider" treatments are significantly higher than those observed in our baseline, No Communication treatment - the approximate $\$ 2.48$ difference in average prices (\$16.24 versus $\$ 13.76$ ) is statistically significant at the $p<0.05$ level. ${ }^{15}$ To examine the stability of cooperation in this treatment, consider differences in average trading prices across the initial and final market periods. Using a matched pairs $t$-test, we reject the null of no difference in average prices across the first and last trading periods: the approximate $\$ 2.65$ difference in average prices ( $\$ 16.24$ versus $\$ 13.59$ ) across these rounds is statistically significant at the $p<0.05$ level.

Combined these data suggest a second result:

Result 2. Group identity has a significant effect on market outcomes. Sellers in mixed markets are unable to sustain a single, cooperative price across market periods.

Fig. 2 which plots average prices by period for both our baseline No Communication treatment and treatment Communication Outsiders highlights data patterns consistent with Result 2. As illustrated in the figure, average trading prices in

\footnotetext{
${ }^{14}$ In this regard, our results share similarity with Bandiera et al. (2005) who show that cooperation amongst fruit pickers breaks down when workers are unable to directly observe and monitor the actions of co-workers. Hence, in their setting, successful cooperation requires more than repeated interaction amongst workers.

${ }^{15}$ The difference in prices is statistically significant if one uses either a parametric $t$-test or a non-parametric Mann Whitney test. For both tests, the relevant unit of observation is the average trading price in the first period for each session (market) within a given treatment. Our test statistic is therefore based on a comparison of four observations for our baseline markets and 20 observations for the pooled "outsider" treatments.
} 
Table 6

Summary statistics by strategy type.

\begin{tabular}{|c|c|c|c|c|c|c|c|c|c|c|c|}
\hline & \multirow[t]{2}{*}{ Frequency } & \multicolumn{2}{|l|}{ Round 1} & \multicolumn{2}{|l|}{ Round 2} & \multicolumn{2}{|l|}{ Round 3} & \multicolumn{2}{|l|}{ Round 4} & \multicolumn{2}{|l|}{ Round 5} \\
\hline & & Price & Volume & Price & Volume & Price & Volume & Price & Volume & Price & Volume \\
\hline Non-Coercive Strategies & $75 \%(15$ of 20$)$ & $17.17(0.98)$ & 1.94 & $15.96(1.71)$ & 3.27 & $15.42(1.63)$ & 4.46 & $14.42(1.52)$ & 5.6 & $13.64(1.24)$ & 6.67 \\
\hline Majority Outsider & 7 & $17.39(0.68)$ & 2 & $16.77(1.01)$ & 2.17 & $16.18(1.29)$ & 3.67 & $15.12(1.35)$ & 5.14 & $14.13(1.26)$ & 6.17 \\
\hline Non-Majority Outsider & 8 & $16.97(0.77)$ & 1.88 & $15.49(1.63)$ & 3.88 & $14.91(1.53)$ & 5 & $13.89(1.31)$ & 6 & $13.26(1.05)$ & 7 \\
\hline Benchmark 0-Only & $35 \%(7$ of 20$)$ & $18.40(0.89)$ & 0.71 & $16.55(2.47)$ & 2.14 & $15.52(1.76)$ & 4 & $14.27(1.55)$ & 5.43 & $13.52(1.25)$ & 6.71 \\
\hline Benchmark 1-Only & $10 \%(2$ of 10$)$ & $16.56(0.73)$ & 4 & $15.94(1.02)$ & 4 & $15.2(1.29)$ & 5 & $14.64(1.00)$ & 5.5 & $13.79(1.05)$ & 7 \\
\hline Hybrid Benchmark - Only & $25 \%(5$ of 20$)$ & $17.68(0.60)$ & 2.2 & $15.74(1.11)$ & 4.2 & $15.5(1.41)$ & 4.8 & $14.62(1.35)$ & 5.8 & 13.69 (1.07) & 6.4 \\
\hline Accommodating & $5 \%(1$ of 20$)$ & $15.8(0.45)$ & 5 & $15.2(0.55)$ & 5 & $15(0.79)$ & 5 & $14(0.0)$ & 6 & $13.93(0.19)$ & 7 \\
\hline Coercive Strategies & $25 \%(5$ of 20$)$ & $14.95(1.73)$ & 4 & $14.47(1.95)$ & 3.6 & $14.39(1.06)$ & 5.2 & $14.38(0.86)$ & 6.6 & $13.46(0.68)$ & 7 \\
\hline Majority Outsider & 3 & 15.55 (2.09) & 3 & $14.40(2.50)$ & 3.33 & $14.07(1.32)$ & 4.67 & $14.68(0.83)$ & 6.33 & $13.69(0.58)$ & 7 \\
\hline Non-Majority Outsider & 2 & $14.45(0.52)$ & 5.5 & $14.56(0.73)$ & 4 & $14.75(0.58)$ & 6 & $13.92(0.61)$ & 6.5 & $13.11(0.59)$ & 7 \\
\hline Undefined Strategies & $20 \%(4$ of 20 ) & $14.55(1.46)$ & 4.5 & $13.91(1.59)$ & 4 & $14.23(1.17)$ & 5.25 & $14.24(0.65)$ & 6.25 & $13.41(0.72)$ & 7 \\
\hline Failed Bench 0 & $5 \%(1$ of 20$)$ & $18.5(0.71)$ & 2 & $18(0.0)$ & 2 & $15(0.0)$ & 5 & $14.86(1.21)$ & 7 & $13.64(0.38)$ & 7 \\
\hline
\end{tabular}

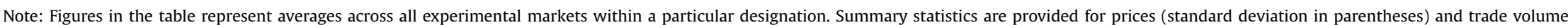
Period 1 of Non-coercive (Benchmarked) Sessions had an average trading price of $\$ 17.45$ with a standard deviation of $\$ 0.98$. On average 1.71 units were purchased in the initial period. 


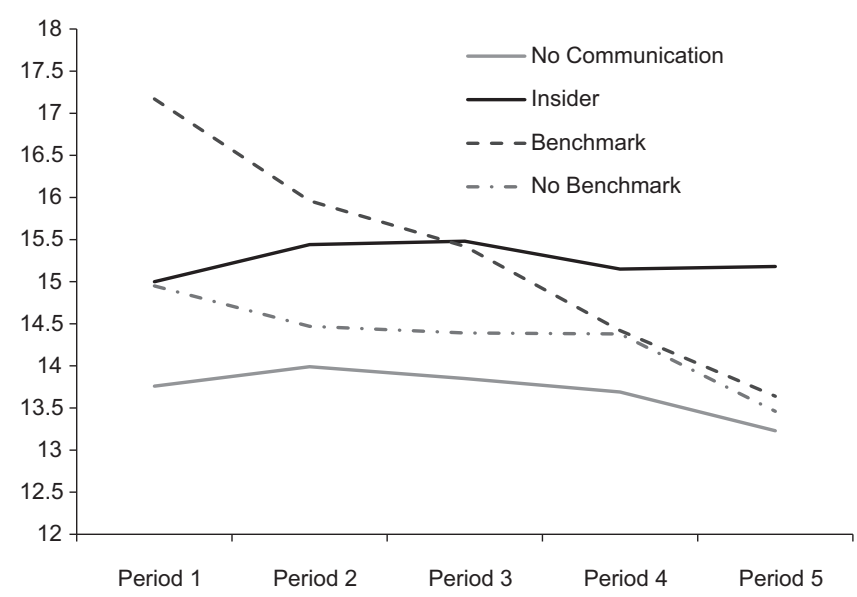

Fig. 3. Average transaction prices - delineated by benchmarking.

the latter treatment are significantly higher than those observed in our baseline markets in the initial trading period. There is a discernable difference in average prices across the initial and final market periods, however, as prices converge rapidly towards competitive benchmarks.

Additional support for Result 2 can be obtained by returning to results from the econometric model presented in Table 5 . Columns 1 and 2 of Table 5 provide insights consistent with the price realizations in Result 2. Average transaction prices in the Communication Outsider treatment are approximately $\$ 2.50$ higher than those observed in the initial period of our baseline (No Communication) treatment - a difference that is significant at the $p<0.05$ level. We observe a similar difference when comparing prices in the initial period across our Communication Insider and Outsider treatments. As note in the third column of Table 5, predicted prices in mixed markets are approximately $\$ 1.26$ higher than those in markets with all inside vendors - a difference that is significant at the $p<0.05$ level.

However, such cooperation is short-lived: the approximate $\$ 2.67$ decline in average prices between the initial and final trading period in our Communication Outsider treatment is significant at the $p<0.05$ level. In fact, by the final market period we are unable to reject the null that average prices in the Communication Outsider treatment equal those for our baseline markets. Furthermore, we are able to reject the null that prices in the "outsider" markets are equal to those in our "insider" treatment. The approximate \$1.59 difference in predicted prices across these treatments is statistically significant at the $p<0.05$ level.

\subsection{Pricing dynamics in "outsider" markets: information effects and benchmarking}

As noted in Section II, there are four distinct strategies that are supportable in our mixed markets - competitive pricing, an accommodating strategy, and two symmetric benchmarks. While the accommodating strategy and both the benchmark 0 and 1 strategies support anti-competitive pricing, they yield very different dynamics and are uniquely identifiable. Under the benchmark 1 strategy, "insiders" each sell a single unit (or less) in the initial period and continue to do so provided total sales volume does not exceed 4 units. The benchmark 0 strategy requires insiders to refrain from trading in the initial period. If a single unit is traded in the initial period, sellers infer that collusion can be sustained and continue selling a single unit in subsequent periods. Under both benchmark strategies, though, we would expect prices in the final period to fall as under the pooling equilibrium non-cooperative outsiders will defect and sell a second unit.

Returning to Table 4, average prices in the initial period for both the Communication Majority Outsider and Communication Non-Majority Outsider treatments exceed competitive levels. Moreover, in both these treatments, prices decline steadily but remain above competitive levels until the final trading periods. To explore whether observed pricing dynamics are consonant with the hypothesized benchmark strategies, we first examine the frequency with which insider vendors are able to "benchmark" the outside vendor.

In 75 percent ( 15 of 20 ) of our outsider markets, insiders are able to support a non-coercive strategy. Of these 15 markets, nearly half demonstrate data patterns consistent with the benchmark 0 strategy - trade volume of one unit or less - and another five involve insiders selling one or two units in the initial period. Our data therefore highlight the importance of information effects on seller behavior - insiders "invest" in learning about the outsider to determine the sustainability of cooperation.

The remaining five markets all involve coercive patterns of trade in the initial period. In three of these markets the outside vendor sells multiple units and/or sells an initial unit at a price lower than $\$ 15.00$. Interestingly, in each of the instances the outside vendor was a majority agent. The remaining two markets were non-majority outsider sessions and have inside vendors selling more than three units in the initial period. While the small sample size precludes statistical 


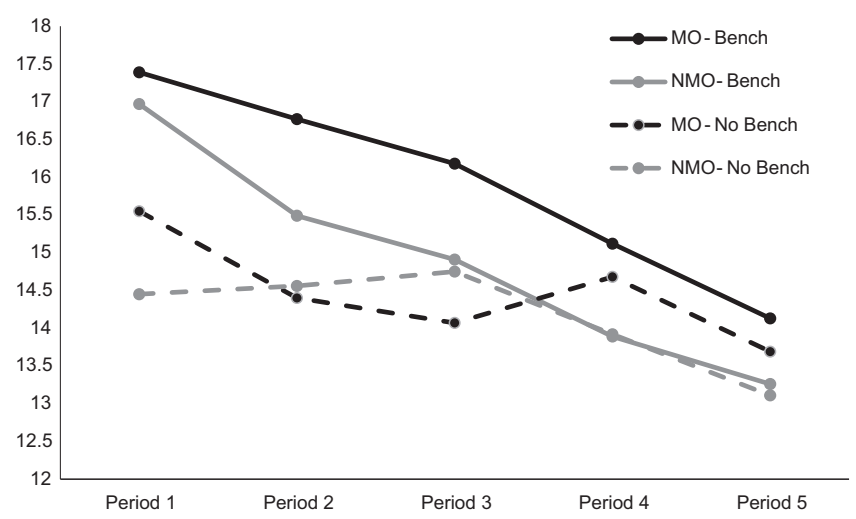

Fig. 4. Average prices - outsider sessions by treatment and benchmarking.

inference, these data suggest that racial composition affects pricing dynamics and defections from potential collusive pricing agreements.

Having documented both successful and failed attempts at benchmarking in the initial trading period, we now explore pricing dynamics across these two market types. In this spirit, consider Table 6 which provides average price and trading volume across these distinct market types. In the third column, we see that the average price in the first trading period of sessions where insiders are able to benchmark the outsider is approximately $\$ 2.22$ greater than that observed in markets without benchmarks. We observe similar differences in the second (third) trading periods - prices are approximately $\$ 1.49$ (\$1.03) greater in benchmarked session. Using a two sample $t$-test, we are able to reject the null of equal prices across these market types at the $p<0.05$ level. ${ }^{16}$

Similar differences emerge if one focuses on trade volume. For example, average trade volume in the first period of sessions where insiders are able to benchmark the outsider is approximately 2.06 units lower than that observed in markets without benchmarks. Using a two sample $t$-test, we are able to reject the null of equal trade volume across these market types at the $p<0.05$ level. Extending the analysis to consider differences in average trade volume in the second (third) trading periods highlight similar differences across session types - trade volume in benchmarked sessions is significantly lower than that observed in sessions without benchmarks.

Although benchmarking facilitates lower trade volume and higher average prices in early market periods, it does not ensure the stability of cooperation in mixed markets. Average prices and overall trade volume converge towards competitive levels and are indistinguishable from those observed in sessions without benchmarking over the final market periods. For example, as noted in Table 6, average prices in the fourth period are approximately $\$ 0.04$ higher in benchmarked sessions. Yet, neither this nor the approximate \$0.18 difference in average prices in the final trading period is significant at meaningful levels. Taken jointly, these data suggest a third result:

Result 3. A majority of our outsider markets display patterns of trade consistent with our model of benchmarking. The use of such strategies impacts prices and trade volume in early market periods. Yet, the effect of benchmarking is short-lived and erodes in later market periods.

Fig. 3 plots average prices by period across outsider markets with and without benchmarking and highlights data patterns consistent with Result 3 . In early market periods, average prices in sessions with benchmarking are significantly higher than those observed in markets without benchmarks and what was found in our Communication Insider treatment. By the final rounds, however, prices are indistinguishable across outsider markets and converge towards those observed in our baseline markets.

Importantly, the existence of benchmarking helps to organize the observed differences in pricing dynamics across insider and outsider treatments. To benchmark the outside vendor, insiders refrain from trading in period 1 across a non-negligible subset of sessions. Lower trade volume translates into higher average prices than those observed in round 1 of our Communication Insider treatment. For example, average trade volume in the first period of a benchmarked session is approximately 1.92 units lower than that observed in the first period of a communication insider session - a difference that is statistically significant at the $p<0.05$ level using both a parametric $t$-test and the non-parametric Mann Whitney test.

In subsequent market rounds, sellers in benchmarked sessions cooperate by setting prices above competitive levels. As benchmarking proves unstable, however, cooperation unravels and average prices fall below those observed in the Communication Insider treatment and ultimately converge towards those observed in the baseline treatment by the final market period. In fact, by the final period both average trade volume (6.67 units) and average trade price (\$13.64) are significantly

\footnotetext{
${ }^{16}$ To provide the most conservative test, we account for data dependencies within a session by using the average price for a given trade period as the unit of observation. The relevant test statistic is thus based on a comparison of fifteen observations from sessions with benchmarks and five observations from sessions without benchmarks. It should be noted that empirical results are robust to the use of the non-parametric Mann-Whitney test.
} 
lower than those observed in the final period of our communication insider treatment (5.43 units traded and an average price of \$15.18) and indistinguishable from those observed in our baseline treatment ( 7.25 units traded and an average price of $\$ 13.23)$.

\subsection{Seller composition and the stability of benchmarks}

Our data are sufficiently rich to examine whether the racial composition of sellers is related to the stability of benchmarks and associated market performance measures. While extant theory does not provide testable hypotheses regarding how the racial composition of sellers within a market should affect pricing decisions, there is experimental evidence suggesting that racial composition (and group identity) may impact trust and hence the stability of cooperative arrangements. For example, Andreoni and Petrie (2004, p. 6) note that "working with familiar others can reduce transactions costs, as familiarity can enhance trust." And, Glaeser et al. (2000) and Fershtman and Gneezy (2001) report evidence from laboratory games that suggests group composition may play an important factor in observed outcomes.

Returning to Table 6, we find that across all market periods, average prices (overall trade volume) in benchmarked sessions of the Communication Majority Outsider treatment are greater than (lower than) those in benchmarked sessions of the Communication Non-Majority Outsider treatment. In all market periods, these observed differences are statistically significant at the $p<0.05$ level using a two-sample $t$-test. Yet, for markets without benchmarks, we observe no such difference - average prices across our Majority and Non-Majority Outsider treatment are statistically indistinguishable.

Further, across all but the final market period, average prices in benchmarked sessions of the Majority Outsider treatment are significantly higher than those observed in sessions without benchmarks. Likewise, sellers in these sessions are able to sustain prices above those observed in our baseline, No Communication treatment. For instance, in the final market period, the approximate $\$ 0.93$ difference in the average price ( $\$ 14.16$ versus $\$ 13.23$ ) is significant at the $p<0.05$ level using a two sample $t$-test.

In contrast, over the final two market periods, average prices in benchmarked sessions of the Non-Majority Outsider treatment are lower than those observed in sessions without benchmarks. Moreover, observed prices in these final two periods fall within the competitive bounds and are indistinguishable from those observed in our baseline. As a whole, these data suggest a fourth result:

Result 4. In "outsider" markets with benchmarking, the racial composition of seller groups impacts the stability of cooperation and pricing dynamics. In "outsider" markets without benchmarking, dynamics are unaffected by the composition of seller groups.

Result 4 shares similarity with Bandiera et al. (2005) who show that social connections (relationships) amongst fruit pickers impact productivity when workers are remunerated via a relative incentive scheme where one's own effort imposes a negative externality on others. However, the relationship amongst workers has no impact on productivity when workers are remunerated via piece rates.

Fig. 4 which presents average transaction prices per period across outsider treatments for sessions with and without benchmarking suggests data patterns consonant with Result 4. As illustrated in the figure, across all market periods prices in benchmarked sessions in treatment Communication Majority Outsider are greater than those in treatment Non-Majority Outsider. When sellers fail to benchmark the "outside vendor, there is no discernable difference in average prices across the Majority and Non-Majority Outsider treatments.

An interesting issue thus revolves around the price adjustment process and the decision of various seller types to deviate by pricing below key thresholds. In this spirit we examine which seller in a market - the local or non-local dealer - first lowers prices below the cooperative level of $\$ 16$ and which seller first lowers prices into the competitive equilibrium range of \$13-14. For the Communication Majority Outsider sessions, the non-local dealer is the first to price below the cooperative benchmark in 65 percent of the sessions, and is the first to price into the CE range in 87.5 percent of the sessions. A test of proportions suggests that the null hypothesis of no difference between the proportion of local and non-local dealers that first deviate cannot be rejected for the former difference but should be rejected at the $p<0.05$ level for the latter. ${ }^{17}$ For the Communication Non-Majority Outsider sessions, the non-local dealer is the first to price below cooperative benchmark in 15.0 percent of the sessions and is the first to price into the competitive range in only 5.0 percent of the sessions. Both of these differences in proportions are significant at the $p<0.05$ level.

A natural question that arises pertains to why we observe such behavioral differences across the outsider treatments. We can do slightly better than speculate on this issue by exploring information gathered in the post-experimental survey. In this case, we can examine whether the actions taken by local (inside) dealers are due to general perceptions of race. When considering responses to questions \#6 and \#7 in the survey (trust questions-see Appendix A), we find that local dealers trust other local dealers more than they trust non-local dealers: 63 percent of local dealers stated they trusted the outside

\footnotetext{
${ }^{17}$ In two of the Communication Majority Outsider sessions prices remain above the competitive range throughout, hence there are only 8 occasions of pricing into the CE range. Ties - occasions where both a local and non-local dealer simultaneously report transaction prices that drop the prevailing market price below the joint profit-maximizing or into the CE range - are recorded as 0.5 of a transaction for each party. Such ties occur in 5 of the 20 reported initial deviations below the joint profit-maximizing level and in 3 of the 18 reported initial deviations into the CE price range.
} 
dealer the least and 73 percent stated they trusted another local dealer the most. These percentages are both significantly different from the percentages of dealers who trusted other insiders the least (19 percent) and who trusted the outsider the most ( 2 percent) using a test of proportions

Interestingly, beliefs about outsiders are consistent across the treatments suggesting that, in aggregate, race is not an important factor in the level of local dealer trust. For example, 17 of 24 local dealers (71 percent) in treatment Communication Non-Majority Outsider indicated that they trusted the non-majority outsider the least. In treatment Communication Majority Outsider, 13 of 24 (54 percent) of the local dealers stated that they trusted the majority outsider the least a difference that is not statistically significant at conventional levels using a test of proportions.

\section{Conclusions}

This study explores the importance of group membership and identity on seller's behavior in markets. Using a series of multilateral decentralized bargaining market treatments, we find that explicit seller communication does not ensure cooperative outcomes in practice. When an outsider joins the seller group, coordination fails, leading to a rapid convergence towards competitive predictions. Moreover, our data suggest that both the stability of cooperation and associated pricing dynamics in such markets depend on the composition of sellers.

The observed effects are all conveniently placed within a conceptual framework highlighting cooperation is possible in a finitely-repeated game if one can construct a group of only insiders in an ongoing relationship. Alternately, if groups contain one or more outsiders, the only stable prices correspond to the set of Nash equilibria. However, we identify an alternative cooperative equilibrium in such settings that requires prices to move through time.

The novelty of our study is that we emphasize how group composition affects the strategies and information available to members, and explore how these factors impact the ability of the group to cooperate. In this regard, our approach is similar in spirit to prior studies such as Becker and Murphy (1988) work on rational addiction, the Kreps et al. (1982) paper on rational cooperation in finitely repeated prisoners' dilemma, or Kandori's (1992) paper on social norms and community enforcement. Rather than invoking a preference based (or behavioral) rationale for unanticipated behavior, we posit a neoclassical framework and explore the smallest departures from the standard model required to explain such outcomes.

Beyond showing the importance of group composition on pricing decisions and the allocation of surplus in a market setting, we believe our research has broader implications. For example, our research suggests a new reason why more fractionalized countries have lower growth (e.g., Easterly and Levine, 1997; Alesina et al., 2003) and more ethnically diverse U.S. cities have smaller spending shares on productive public goods (Alesina et al., 1999). Ethnic and linguistic differences could lead to reduced within-group interactions and less knowledge about how diverse group members will behave. Hence, such groups face more difficult strategic challenges when attempting to cooperate making it more difficult to take advantage of economic opportunities.

Similarly, our results accord well with previous work exploring the link between trust and growth (Knack and Keefer, 1997), and suggest a reason why bilateral trust affects patterns of trade and investment flows amongst European nations (Guiseo et al., 2009). In our setting, insiders tend to trust outsiders less than other insiders. The presence of outsiders, therefore, deters cooperation and serves to crowd-out potentially profitable actions. Finally, our results highlight that insiders are willing to make costly efforts to learn about the behavior of outsiders. This finding provides micro-level evidence consistent with the general equilibrium model of Zak and Knack (2001), in which low trust environments lead to lower equilibrium rates of investment and growth as agents must undertake costly efforts to learn about the trustworthiness of others.

\section{Appendix A. Experimental protocol}

This appendix provides an overview of how sellers for our experiment were recruited and how we identified the different seller types - insiders and outsiders. At the start of each day and before the market was opened to the public, an experimental monitor canvased the floor of the sportscard show (aisles of the flea market) and approached vendors who had rented a table at the show (flea market) to inquire whether they would be interested in participating in an economics experiment later that day that would take approximately an hour minutes to complete.

If the vendor agreed to participate in the experiment, the monitor asked where they were from and if they frequented the given sales site in the past. We used this information to "type" sellers. Specifically, inside vendors were those from the local area who frequented the given sales site. Whereas outside vendors were those from an outside area who did not frequent the given sales site often.

At the designated time, the experimental monitor gathered the various vendors in a central location and read the experimental instruction (reproduced below) aloud. After the instructions had been read and any questions answered in private, each seller was handed their seller's card and allowed to speak for a fixed amount of time (3 min) with the other vendors in the experiment. Sellers then returned to the tables that they had rented for the show (flea market) and the correspond trading round opened. 
Concurrently, buyers were gathered in another central location and read the experimental instructions. Once the instructions were read and questions answered, each buyer was provided a buyer's card along with information on the locations of all sellers in the marketplace. Buyers were instructed that they were to approach the sellers to negotiate a potential purchase once the market was opened. ${ }^{18}$

During each market period, if a buyer and seller agreed upon a trade they both approached a monitor stationed at a central location and reported the agreed upon transaction price. At this time, the monitor recorded the trade price and sent a second monitor around to the remaining vendors to announce that a transaction had occurred along with the price at which it occurred. Importantly, these announcements provided no information about the identities of the buyer/seller who executed the trade.

At the end of each ten minute trading period, this same process began again with buyers and sellers gathered in a central location and provided a new buyer/seller card. In sessions that allowed explicit seller communication, sellers were then afforded the opportunity to talk amongst each other after which they returned to their tables and the market opened for the next round of play.

\section{A.1. General instructions - Chamberlin market}

Today, we are going to set up a market in which some of you will be buyers and some of you will be sellers. The commodity to be traded is divided into distinct items, or "units". We will not specify a name for the commodity; we will simply refer to units.

Trading will occur in a sequence of trading rounds. The prices that you negotiate in each round will determine your earnings. You will be paid all earnings for the session at the end of the session in cash.

The experiment will consist of 7 rounds. The first 2 rounds will be practice and will not affect your earnings for the experiment.

\section{A.1.1. Valuations and earnings}

Prior to the start of each round, sellers will be provided a seller's card. The number on the sellers' card is known as their "cost". Your cost represents the minimum amount for which you can sell a unit. This information contained on the seller's card is strictly private and a seller's costs may change each round.

Sellers earn money by selling units at prices that are above their cost. Earnings from the sale of each unit are the difference between the sale price and the cost. For example, if a seller has a cost of $\$ 10$ and sells their unit for $\$ 15$, they earn $\$ 15-\$ 10=\$ 5$.

If a seller does not sell their unit, they earn exactly zero that round. You will only be allowed to sell at a price equal to or greater than your cost. If you attempt to sell a unit at a price that is less than your cost, your trade will be canceled.

Prior to the start of each round, buyers will be provided a buyer's card. The number on the buyers' card is known as their "value". Your value is represents the maximum amount for which you can purchase a unit. The information contained on the buyer's card is strictly private and a buyer's value may change each round.

Buyers earn money by buying units at prices that are below their value. Earnings from the purchase of each unit are the difference between the value and the purchase price. For example, if a buyer has a value of $\$ 20$ and buys a unit for $\$ 12$, they earn $\$ 20-\$ 12=\$ 8$.

If a buyer does not buy a unit, they earn exactly zero that round. You will only be allowed to buy at a price equal to or below your value. If you violate attempt to purchase a unit at a price that is greater than your value, your trade will be cancelled.

In addition to earnings from buying (selling) at a price that is less than your value (greater than your cost), we will provide a commission of $25 \leftarrow$ to both the buyer and seller for each unit traded.

\section{A.1.2. The trading rounds}

Each trading round will be $5 \mathrm{~min}$ long. During the round, you can approach anyone to negotiate a potential sale/purchase. There are three rules that you must follow during the experiment.

1. You are not allowed to threaten or intimidate other traders.

2. You are not allowed to discuss or disclose your cost or value with any other trader.

3. You are not allowed to discuss pots-session side payments with any other trader.

If you violate any of these rules, you will be asked to leave the experiment and will earn nothing for participating.

If you make a trade, you and your partner should approach me immediately and inform me of the trade price to confirm that it is a legitimate trade. Remember that you cannot trade in a way that gives you negative earnings. That means sellers can only trade at a price above their cost and buyers can only trade at a price below their value.

\footnotetext{
${ }^{18}$ The physical layout of our various markets differed across locations and time, although vendors were always within a few rows of each other and there was no systematic difference in the spatial proximity of inside and outside vendors to other sellers in the market.
} 
After any pair trade and I have a record of their trade price, I will call out their trade price so that all the remaining participants can hear it.

\section{A.1.3. Confidential survey}

These questions will be used for statistical purposes only. THIS INFORMATION WILL BE KEPT STRICTLY CONFIDENTIAL AND WILL BE DESTROYED UPON COMPLETION OF THE STUDY.

1. How long have you been active in the sportscards and memorabilia market?

2a. In a typical month, how often do you visit this area as a sportscard dealer?

2b. As a dealer, how often do you plan to set up in this area in the coming months?

3. Gender: 1) Male 2) Female

4. Age __ Date of Birth

5 . What is the highest grade of education that you have completed? (Circle one)

1) Eighth grade 3) 2-Year College 5) 4-Year College

2) High School 4) Other Post-High School 6) Graduate School Education

6. Which of the other dealers did you trust the least when you were discussing how to sustain higher prices in the market? (insert name) or:

you trusted them all the same (circle).

7. Which of the other dealers did you trust the most when you were discussing how to sustain higher prices in the market? (insert name) or:

you trusted them all the same (circle)

\section{Appendix B. Supplementary material}

Supplementary data associated with this article can be found in the online version at http://dx.doi.org/10.1016/j.euro ecorev.2016.02.019.

\section{References}

Akerlof, George A., Kranton, Rachel E., 2000. Economics and identity. Q. J. Econ. 115, 715-753.

Alesina, Alberto, Baqir, Reza, Easterly, William, 1999. Public goods and ethnic divisions. Q. J. Econ. 114, 1243-1284.

Alesina, Alberto, Devleeschauwer, Arnaud, Easterly, William, Kurlat, Sergio, Wacziarg, Romain, 2003. Fractionalization. J. Econ. Growth 8, 155-194. Andreoni, James, Petrie, Ragan, 2004. Beauty, Gender, and Stereotypes: Evidence from Laboratory Experiments. University of Wisconsin.

Aoyagi, Masaki, Frechette, Guillaume R., 2008. Collusion as public monitoring becomes noisy: experimental evidence. J. Econ. Theory 144, $1135-1165$. Apesteguia, Jose, Dufwenberg, Martin, Selten, Reinhard, 2007. Blowing the whistle. Econ. Theory 31, 143-166.

Bandiera, Oriana, Barankay, Iwan, Rasul, Imran, 2005. Social preferences and the response to incentives: evidence from personnel data. Q. J. Econ. 120, 917-962.

Becker, Gary S. Murphy, Kevin M., 1988. A theory of rational addiction. J. Polit. Econ. 96, 675-700.

Benoit, JeanPierre, Krishna, Vijay, 1985. Finitely repeated games. Econometrica 53, 901-922.

Bigoni, Maria, Fridolfsson, Sven-Olof, Coq, Chloe Le, Spagnolo, Giancarlo, 2012. Fines, leniency, and rewards in antitrust. RAND J. Econ. 43, 368-390. Chamberlin, Edward H., 1948. An experimental imperfect market. J. Polit. Econ. 56 (2), 95-108.

Charness, Gary, Rigotti, Luca, Rustichini, Aldo, 2007. Individual behavior and group membership. Am. Econ. Rev. 97, 1340-1352.

Chen, Yan, Li, Sherry, 2009. Group identity and social preferences. Am. Econ. Rev. 99, 431-457.

Compte, Olivier, 1998. Communication in Repeated Games With Imperfect Private Monitoring. Econometrica 66, 597-626.

Coser, Lewis A., 1956. The Functions of Social Conflict, Glencoe, ILFree Press.

Daughetry, Andrew, Reinganum, Jennifer, 2011. A dynamic model of lawsuit joinder and settlement. RAND J. Econ. 42, 471-494.

Davis, Douglas, Holt, Charles, 1993. Experimental Economics. Princeton University Press, Princeton.

Davis, Douglas, Holt, Charles, 1998. Conspiracies and secret discounts in laboratory markets. Econ. J. 108, 736-756.

Easterly, William, Levine, Ross, 1997. Africa's growth tragedy: policies and ethnic divisions. O. J. Econ. 112, 1203-1250.

Eckel, Catherine C., Grossman, Phillip J., 2005. Managing diversity by creating team identity. J. Econ. Behav. Organ. 58, 371-392.

Farrell, James, Saloner, Garth, 1985. Standardization, compatibility, and innovation. RAND J. Econ. 16, 70-83.

Fershtman, C., Gneezy, U., 2001. Discrimination in a segmented society: an experimental approach. Q. J. Econ. 116, 351-377.

Genesove, David, Mullin, Wallace P., 2001. Rules, communication, and collusion: narrative evidence from the sugar institute case. Am. Econ. Rev. 91 379-398.

Glaeser, E., Laibson, D., Scheinkman, J., Soutter, C., 2000. Measuring trust. Q. J. Econ. 115, 811-846.

Goette, Lorenz, Huffman, David, Meier, Stephan, 2006. The impact of group membership on cooperation and norm enforcement: evidence using random assignment to real social groups. Am. Econ. Assoc. Pap. Proc. 96, 212-216.

Grether, David, Plott, Charles, 1984. The effects of market practices in oligopolistic markets: an experimental examination of the ethyl case. Econ. Inq. 22 479-507.

Guiseo, Luigi, Sapienza, Paola, Zingales, Luigi, 2009. Cultural biases in economic exchange? Q. J. Econ. 124, 1095-1131.

Hargreaves Heap, Shaun P., Zizzo, Daniel John, 2009. The value of groups. Am. Econ. Rev. 99, 295-323.

Harrison, Glenn W., List, John A., 2004. Field experiments. J. Econ. Lit. 42, 1009-1055.

Hinloopen, Jeroen, Soetevent, Adriaan, 2008. Laboratory evidence on the effectiveness of corporate leniency programs. RAND J. Econ. 39, 607-616.

Hong, James, Plott, Charles, 1982. Rate filing policies for inland water transportation: an experimental approach. Bell Journal of Economics, 13. Spring1-19. Isaac, R. Mark, Plott, Charles, 1984. The opportunity for conspiracy in restraint of trade. J. Econ. Behav. Organ. 5, 1-30.

Isaac, R. Mark, Ramey, Valerie, Williams, Arlington, 1984. The effects of market organization on conspiracies in restraint of trade. J. Econ. Behav. Organ. 5 , $191-222$.

Joyce, Patrick, 1983. Information and behavior in experimental markets. J. Econ. Behav. Organ. 4, 411-424. 
Kandori, Michihiro, 1992. Social norms and community enforcement. Rev. Econ. Stud. 59, 61-80.

Kandori, M., Matsushima, H., 1998. Private observation, communication, and collusion. Econometrica 66, 627-652.

Knack, Stephen, Keefer, Philip, 1997. Does social capital have and economic payoff? A cross-country investigation. Q. J. Econ. 112, $1251-1288$.

Klor, Esteban F., Shayo, Moses, 2010. Social identity and preferences over redistribution. J. Public Econ. 94, $269-278$.

Kreps, David M., Milgrom, Paul, Roberts, John, Wilson, Robert, 1982. Rational cooperation in the finitely repeated prisoners' dilemma. J. Econ. Theory 27, 245-252.

Kuhn, Kai-Uwe, 2001. Fighting collusion by regulating communication between firms. Econ. Policy 16, 167-204.

Leider, Stephen, Mobius, Markus M., Rosenblat, Tanya, Do, Quoc-Anh, 2009. Directed altruism and enforced reciprocity in social networks. Q. J. Econ. 124, 1815-1851.

Li, Sherry, Dugan, Katsul, Haruvy, Ernan, 2011. Group identity in markets. Int. J. Ind. Organ. 29, $104-115$.

List, John A., 2004. Testing neoclassical theory in multi-lateral decentralized markets. J. Polit. Econ. 112, 1131-1156.

List, John A., Price, Michael K., 2005. Conspiracies and secret price discounts in the marketplace: evidence from field experiments. Rand J. Econ. 36, 700-717.

Miller, Arthur H., Gurin, Patricia, Gurin, Gerald, Malanchuk, Oksana, 1981. Group consciousness and political participation. Am. J. Polit. Sci. 25, 494-511.

Murphy, Robert F., 1957. Intergroup hostility and social cohesion. Am. Anthr. 59, 1018-1035.

Rojas, Christian, 2012. The role of demand information and monitoring in tacit collusion. RAND J. Econ. 43, 78-109.

Sherry, John F., 1990. A sociocultural analysis of a midwestern American flea market. J. Consum. Res. 17, 13-30.

Smith, Vernon L., 1965. Experimental auction markets and the Walrasian hypothesis. J. Polit. Econ. 73, 387-393.

Sumner, W. Graham, 1906. Folkways. Ginn, New York.

Tajfel, Henri, John, Turner, 1979. An integrative theory of intergroup conflict, In: Stephen, Worchel, William, Austin (Eds.), The Social Psychology of Intergroup Relations, Brooks/Cole, Monterey, CA

Zak, Paul J., Knack, Stephen, 2001. Trust and growth. Econ. J. 111, 295-321. 